\title{
Erken Gebelikte Kullanılan Vajinal, İntramuskuler veya Kombine Progesteronun Serum Progesteron Düzeylerine Etkisinin Karşılaştırılması
}

\section{Comparison of The Effect of Vaginal, Intramuscular or Combined Progesterone on Serum Progesterone Levels in Early Pregnancy}

\author{
Fatih YAĞBASAN ${ }^{1}(\mathbb{D})$, Mehmet Murat IȘIKALAN ${ }^{1}(\mathbb{D})$, Mehmet Cengiz ÇOLAKOĞLU 1
}

\author{
1 Necmettin Erbakan Üniversitesi, Meram Tıp Fakültesi Kadın Hastalıkları ve Doğum Anabilimdalı, Konya,TÜRKIYE
}

Öz.

Amaç: Erken gebelik haftasında düşük tehdidi endikasyonu altında başlanılan vajinal, intramuskuler (IM) veya kombine (vaginal+ IM) progesteron preparatlarının serum progesteron düzeylerine etkisinin karşılaştıııması. Materyal ve metod: Aralık 2018- Aralık 2019 tarihleri arasında kliniğimize düşük tehdidi nedeniyle başvuran ve progesteron uygulanan ilk trimester gebeler çalışmaya dahil edildi. Katılımcılar vajinal progesteron, İM progesteron veya vajinal + IM progesteron tedavisi almalarına göre üç gruba ayrıldı. Grupların ilk ilaç dozundan sonraki 3. saat ve 7. günde ölçülen serum progesteron düzeyleri, serum progesteron seviyelerinin optimal değere ulaşım hızları ve uygunlukları karşılaştıııldı.

Bulgular: Çalışmamıza progesteron tedavisi alan 64 hasta katılmıştır. Bunlardan 23 hasta (\%35.9) intramuskuler, 19 hasta (\%29.7) vajinal, 22 hasta ise (34.4) vajinal + intramuskuler progesteron kullanan hastalardı. Gruplar arasında progesteron başlama haftası, yaş, gravida ve parite özellikleri açısından anlamlı fark bulunmamıştır. Vajinal +iM progesteron kullanan grubun başvuru sırasında progesteron düzeyleri diğer gruplara göre anlamlı derecede düşük saptanmıştır $(p=0.013)$. Vajinal $+i M$ progesteron kulllanan grubun hem 3 . saatteki hem 7.gündeki serum progesteron seviyesindeki artış oranı, diğer iki gruba (vajinal ve IM) oranla anlamlı derecede yüksek bulunmuştur (sırayla $p=0.001, p=0.006$ ).

Sonuç: Erken gebelik haftalarında düşük tehditi olan hastaların kesin tedavisi yoktur, ancak progesteron tedavisinin son yıllarda önerildiği çalışmalar artmaktadır. Bu çalışmada vajinal+ IM kombine progesteron preparatlarının serum progesteron seviyelerini daha hızlı artırdığı belirlenmiştir. Fakat konu ile ilgili çalışmamız yeterli olmayıp ek çalışmalara intiyaç vardır.

Anahtar Kelimeler: Düşük tehdidi, Gebelik, Serum progesteron

\section{Abstract}

Background: This study aimed to compare the effect of vaginal, intramuscular (IM) or combined (vaginal + IM) progesterone preparations initiated under the indication of threatened abortion at early gestational week on serum progesterone levels.

Materials and Methods: First-trimester pregnant women who applied to our clinic between December 2018 and December 2019 due to the threatened abortion and who received progesterone were included in the study. The participants were divided into three groups according to whether they received vaginal progesterone, IM progesterone or vaginal + IM progesterone treatment. The serum progesterone levels measured on the 3rd hour and 7 th day after the first drug dose of the groups and the rates of serum progesterone reaching the optimal value were compared.

Results: Sixty-four patients who received progesterone treatment participated in our study. Twenty-three (35.9\%) of these patients were using intramuscular progesterone, $19(\% 29.7)$ were using vaginal progesterone and 22 (34.4\%) were using vaginal + intramuscular progesterone. There was no significant difference between the groups in terms of progesterone onset week, age, gravida and parity characteristics. The levels of progesterone at admission of the group using vaginal + IM progesterone were significantly lower than the other groups $(p=0.013)$. The increased rate of serum progesterone levels in both the 3rd hour and the 7th day of the group using vaginal + IM progesterone was found to be significantly higher compared to the other two groups (vaginal and IM) ( $p=$ $0.001, p=0.006$, respectively).

Conclusion: There is no definitive treatment for patients with threatened abortion in early gestational weeks, but studies in which progesterone treatment is recommended in recent years are increasing. In this study, it was determined that vaginal + IM combined progesterone preparations increased serum progesterone levels faster. However, our study on the subject is not sufficient and additional studies are needed.

Key words: Threatened abortion, Pregnancy, Serum progesterone

\section{Sorumlu Yazar I \\ Corresponding Author}

Dr. Mehmet Murat IŞIKALAN

Necmettin Erbakan Üniversitesi Meram Tıp Fakültesi Kadın

Hastalıkları ve Doğum Anabilimdalı, Konya

e-mail: muratisikalan@gmail.com

Tel: 0505-6167184

Geliş tarihi / Received:

01.07.2020

Kabul tarihi / Accepted: 22.12.2020

DOI: 10.35440/hutfd.761669

Bu çalışma Dr. Fatih YAĞBASAN'ın tıpta uzmanlık tezinden türetilmiştir. 


\section{Giriş}

Düşük tehdidi (DT), vajinal kanama ve abdominal kasıımalar ile ortaya çıkan, sık gözlenen bir gebelik komplikasyonudur. İlk trimesterdeki gebelerin yaklaşık \%15-20'sinde görülür ve bu gebeliklerin hemen hemen yarısı düşük ile sonuçlanmaktadır $(1,2)$. Illk trimester vajinal kanamalarının tamamı düşük ile sonuçlanmasa da bu fetüsler erken doğum, düşük doğum ağırlığı ve prenatal ölüm açısından daha yüksek risk grubunda bulunmaktadırlar (3). Birçok çalışmada DT tanısı alan gebelerde progesteron kullanımının gebelik kayıplarını azaltabileceği belirtilmiştir (4-9).

Progesteron, gebeliğin implantasyonu ve gelişmesi için belirli miktarda üretilmesi gereken ve başlangıçta korpus luteumdan salgılanan steroid yapıda bir hormondur. Endometriumda sekretuar değişiklikleri başlatmasına ve erken gebeliği desteklemesine ilaveten, uterin kasları gevşetmekte ve maternal immün yanıtı düzenleyip fetal rejeksiyona engel olmaktadır (10). Progesteron özellikle erken dönemlerde gebeliğin devamı için önemli bir rol oynamaktadır. Illerleyen haftalarda gebeliğin devamı açısından, düşük progesteron düzeylerinin önemi azalmakta, yapısal uterin anomaliler veya servikal yetmezlik gibi durumlar hormonal sebepleri geride bırakmaktadır. Bu tür durumlarda servikal serklaj gibi cerrahi yöntemler medikal girişimlerden daha öncelikli olarak tercih edilmektedir(11). DT ve tekrarlayan gebelik kayıplarının tedavisinde progesteron desteği obstetri pratiğinde uzun zamandır yaygın olarak verilmekte olan bir tedavi seçeneği olmuştur. Ancak DT'ni azaltmak için progesteron kullanımı tartışmalı bir konudur $(12,13)$. Progesteron kullanımının preterm doğumu önlemedeki etkinliği hasta yapısına ve progesteronun türevine, dozuna ve veriliş yoluna bağlı olarak değişiklik göstermektedir (14, 15). Hidroksiprogesteron kaproat (IM), natürel (IM) yada mikronize progesteron (vajinal, oral), vajinal jel yada oral progesteron türevleri tedavi seçenekleri arasında yer almaktadır. Bizim bilgilerimize göre birinci trimester DT olan hastaların 3 farklı progesteron tedavi grubu oluşturarak serum progesteron seviyelerini karşılaştıran bir çalışmaya rastlanmamıştır. Bu çalışmamızda progesteron türevlerinin serum progesteron seviyesini etkin ve ideal seviyeye en hızlı şekilde ulaştıran veriliş yolunu belirlemek amaçlanmıştır.

\section{Materyal ve Metod}

Bu retrospektif çalışmada Aralık 2018- Aralık 2019 tarihleri arasında $18-45$ yaş aralığında ilk trimester gebe olup DT nedeniyle kliniğimizde progesteron tedavisi alan hasta dosyaları tarandı. Çalışma için Necmettin Erbakan Üniversitesi Meram Tıp Fakültesi lllaç ve Tıbbi Cihaz Dışı Araştırmalar Etik Kurulundan etik onam alınmıştır (Tarih:10.01.2020; karar no:2020/2269) Intrauterine fetal pol görülmüş ve 14 haftayı geçmemiş gebeler çalışmaya dahil edildi. Kliniğimizde vajinal progesteron olarak Progestan ${ }^{\circledR}$
$200 \mathrm{mg}$, iM progesteron olarak da Progynex® $50 \mathrm{mg}$ kullanılmaktadır. Vajinal progesteron $2 \times 1$, IM progesteron $1 \times 1$ ve vajinal + IM progesteron ise $1 \times 1$ pozoloji olarak uygulanmıştır. Hastaneye yatış öncesi progesteron kullanan, hastaneye yattıktan sonra belirtilen uygulama şekli, doz ve pozoloji dışında progesteron kullanan veya kullanım öncesi ve sonrası serum progesteron seviyesi ölçülmeyen hastalar çalışmaya dahil edilmedi. Hastaların demografik ve obstetrik bilgilerinin yanısıra, progesteron almadan önceki, aldıktan 3 saat ve 7 gün sonraki serum progesteron seviyeleri kaydedildi. Bunun sebebi progesteronun alındık$\tan 1$ 1-3 saat sonra plazmada en yüksek seviyeye ulaşması ve yarı ömrünün ise yaklaşık 25-50 saat arasında olmasıdır. 3 saat sonraki seviyeler maksimum seviyeler ve 7 gün sonraki seviyelerde progesteronun tamamen metabolize olacağı dönemler olarak düşünüldü.

Düşük tehdidi tanısı, ultrasonografik olarak serviksin kapalı olduğu ve intrauterin gebelik kesesiyle birlikte fetal aktivite izlenen gebelikler olarak tanımlandı. Erken gebelik kaybı tanısında oldukça güvenilir olan transvajinal ultrason kullanıldı (16). Progesteron endikasyonu ve dozları ASRM (American Society for Reproductive Medicine) bülteni baz alınarak belirlendi(17).

Hastalara ait veriler; hastaların yaşı, gebelik haftası, gravida sayısı, ek hastalık bilgileri, serum progesterone seviyeleri, dosya kayıtları ve hastane elektronik arşiv veri tabanı olan 'ENLIL HBYS' kullanılarak elde edildi. Hasta serum progesteron seviyeleri sarı kapaklı vakumlu plastik jelli tüplere alınıp "Elecsys Progesterone III " kitleri bulunan " Roche HITACHI Cobas E601 "tipi cihazlarda çalışılmıştır. İstatiksel analiz için toplanan tüm veriler Statistical Package for the Social Sciences, sürüm 20, Chicago, IL (SPSS) ile analiz edildi. İlgili değişkenler için tanımlayıcı karekteristikler hesaplandı. Verilerin normal dağılımları Kolmogorov-Smirnov testi ile değerlendirildi. Parametrik dağılım gösteren veriler ortalama \pm standart sapma, nonparametrik dağılım gösteren veriler ortanca (25-75 çeyrekler arası aralık), kategorik değişkenler ise sayı (yüzde) olarak gösterildi. Parametrik dağı̈ım gösteren verilerin çoklu grup karşılaşıırması için tek yönlü varyans analizi (ANOVA) testi yapıldı. Nonparametrik dağılım gösteren grupların çoklu karşılaştırması için Kruskal-Wallis testi yapıldı. Posthoc değerlendirme için Mann Whitney $U$ testi ve Bonferoni düzeltmesi yapıldı. İstatistiksel anlamlılık değeri p 0,05 altında olan değerler olarak tanımlandı.

\section{Bulgular}

Çalışmamıza DT nedeniyle progesteron tedavisi alan 64 gebe değerlendirilmiştir. Bunların 23 hasta (\%35.9) intramuskuler, 19 hasta (\%29.7) vajinal, 22 hasta (34.4) vajinal + intramuskuler progesteron kullanan hastalardı.

Çalışmaya katılan her üç grupta progesteron başlama haftaları ve yaş ortalamaları arasında anlamlı fark bulunma- 
mıştır ( $p$ değerleri sırasıyla 0.358, 0.222). Başvuru sırasındaki progesteron değerlerin ortalaması vajinal grupta 17.6 $\mathrm{ng} / \mathrm{ml}$, IM grupta $16.5 \mathrm{ng} / \mathrm{ml}$, vajinal+IM grupta ise 13.6 $\mathrm{ng} / \mathrm{ml}$ olarak izlenmiş olup ,vajinal +IM kullanan grubun ortalama değeri diğer gruplara anlamlı derecede düşük saptanmıştır $(p=0.013)$ (Tablo 1)

Tablo 1. Çalışma gruplarının demografik, obstetrik özelliklerinin ve serum progesteron değerlerinin dağılımı

\begin{tabular}{|l|l|l|l|l|}
\hline & $\begin{array}{l}\text { Vajinal } \\
(\mathbf{n = 1 9 )}\end{array}$ & ì (n=23) & $\begin{array}{l}\text { Vajinal+iM } \\
(\mathbf{n = 2 2})\end{array}$ & $\begin{array}{l}\text { P de- } \\
\text { ğeri }\end{array}$ \\
\hline Yaş (yıl) & $28.5 \pm 5.7$ & $29.3 \pm 5.1$ & $31.3 \pm 5.0$ & 0.222 \\
\hline Gravida & $2(1,2)$ & $3(1,4)$ & $2(1,3)$ & 0.058 \\
\hline $\begin{array}{l}\text { Gebelik haf- } \\
\text { tası (hafta) }\end{array}$ & $8.2 \pm 2.7$ & $7.5 \pm 2.0$ & $8.7 \pm 3.0$ & 0.358 \\
\hline Doğum & $0(0,1)$ & $1(0,2)$ & $1(0,2)$ & 0.106 \\
\hline Yaşayan & $0(0,1)$ & $1(0,2)$ & $1(0,2)$ & 0.125 \\
\hline P0(ng/ml) & $\begin{array}{l}17.6 \\
(9.9,33.0)\end{array}$ & $\begin{array}{l}16.5 \\
(12.3,24.0)\end{array}$ & $\begin{array}{l}13.6 \\
(4.9,15.9)\end{array}$ & $\mathbf{0 . 0 1 3}$ \\
\hline P3(ng/ml) & 21.9 & 23.5 & 21.7 & 0.879 \\
& $(17.2,34.1)$ & $(15.8,29.9)$ & $(12.1,38.9)$ & \\
\hline P7(ng/ml) & 28.1 & 33.5 & 33.0 & 0.665 \\
& $(24.0,40.1)$ & $(25.6,56.0)$ & $(21.7,46.0)$ & \\
\hline
\end{tabular}

IM: Intramuskuler P0: Başvuru sırasında serum progesteron seviyesi P3: Üçüncü saat serum progesteron seviyesi P7: Yedinci gündeki serum progesteron seviyesi

Normal dağılım gösteren veriler ortalama \pm standart sapma, normal dağılım göstermeyen veriler ise ortanca (\%25, \%75 çeyrekler arası aralık) olarak verilmiştir. Anlamlı p değerleri koyu font olarak gösterilmiştir.

Tablo 2. Hastaların serum progesteron değerlerinin 3. saat ve 7. gündeki artış yüzdelerinin gruplara göre karşılaştırılması

\begin{tabular}{|c|c|c|c|c|c|c|}
\hline & $\begin{array}{l}\text { Vajinal } \\
(n=19) \\
\text { (A) }\end{array}$ & $\begin{array}{l}\text { IM } \\
(n=23) \\
(B)\end{array}$ & $\begin{array}{l}\text { Vajinal } \\
+ \text { iM } \\
(n=23) \\
\text { (C) }\end{array}$ & $A$ vs $B$ & B vs $C$ & $\begin{array}{l}\text { A } \\
\text { V } \\
\text { C }\end{array}$ \\
\hline $\begin{array}{l}\text { 3.saat- } \\
\text { teki P } \\
\text { artıs } \\
\text { yüzdesi } \\
(\%)\end{array}$ & $\begin{array}{l}32.1 \\
(12.5, \\
67.3)\end{array}$ & $\begin{array}{l}16.7 \\
(2.2 \\
42.0)\end{array}$ & $\begin{array}{l}88.5 \\
(48.6 \\
237.2)\end{array}$ & 0.754 & $<0.001$ & 0.005 \\
\hline $\begin{array}{l}\text { 7.gün } P \\
\text { artışı } \\
\text { yüzdesi } \\
(\%)\end{array}$ & $\begin{array}{l}80.0 \\
(36.9 \\
132.8)\end{array}$ & $\begin{array}{l}102.6 \\
(29.1 \\
140.0)\end{array}$ & $\begin{array}{l}206.4 \\
(127.2 \\
399.8)\end{array}$ & 1.0 & 0.001 & 0.006 \\
\hline
\end{tabular}

Veriler ortanca (\%25, \%75 çeyrekler arası aralık) olarak verilmiştir. Anlamlı p değerleri koyu font olarak gösterilmiştir.

iM: intramuskuler. P: Progesteron

Çalışmaya katılan üç grubun (vajinal progesteron, IM progesteron ve vajinal +iM progesteron kullananlar) progesteron kullanımından önceki, 3 saat sonraki ve 7 gün sonraki serum progesteron seviyelerindeki artıs oranları yüzde olarak hesaplandı. Üç grubun 3. saat ve 7. gündeki serum progesteron seviyelerinin 0 . saate göre artış oranları karşılaştırıldı. Vajinal +iM progesteron kullanan grubun 3. saatteki serum progesteron seviyesindeki artış oranı sadece vajinal progesteron kullanan gruba oranla anlamlı derecede yüksek bulunmuştur (ortanca değerler $\% 88.5$ vs $\% 32.1, p=$ 0.005). Yine vajinal +iM progesteron kullanan grubun 3 . saatteki serum progesteron seviyesindeki artış oranı sadece IM progesteron kullanan gruba oranla anlamlı derecede yüksek bulunmuştur (ortanca değerler \%88.5 vs
\%16.7, $p<0.001$ ). Ayrıca vajinal +iM progesteron kullanan grubun 7. gündeki serum progesteron seviyesindeki artış oranı sadece vajinal ve sadece IM progesteron kullanan gruba oranla anlamlı derecede yüksek bulunmuştur (sırayla $p=0.001, p=0.006$ ) (Tablo 2 ).

\section{Tartışma}

$\mathrm{Bu}$ çalışmamızda DT hastalarında düşükleri azaltmak adına kullanılan progesteron tedavisinin en hızlı şekilde dolaşıma girip etki gösterdiği uygulama yolunu tespit etmeyi amaçladık. Literatüre bakıldığında, çoğu çalışmada progesteron kullanımı sonrası gebelik sonuçları araştırılmıştır. Bazı çalışmalarda erken gebelik kayıplarının önlenmesinde kullanılan vajinal progesteron ile intramuskuler progesteron arasında anlamlı bir fark görülmemiştir (18). Ancak yapılan bu çalışmalar gebelik sonuçları açısından değerlendirilmiş olup serum progesteron seviyesine etkisi hakkında yeterli çalışma bulunmamaktadır.

Wahabi ve arkadaşları 2018 yılında yaptıkları bir derlemede DT tedavisinde progesteron ve türevlerinin güvenliğini ve etkinliğini belirlemeyi amaçlamışlar (19). Bu derlemede 7 farkı makale (696 katılımcı) değerlendirilmiştir. Bu çalışmada progesteron kullanımının hiç tedavi almayanlara ya da plaseboya göre düşük oranını azalttığı saptanmıştır (risk oranı (RR) 0.64, \%95 güven aralığı (Cl) 0.47$0.87)$. Hiç tedavi almayan grup ile oral progesteron tedavisi alanlar kıyaslandığında oral progesteron alanların abort oranları anlamlı düzeyde düşük saptanmış; (RR 0.57, \%95 Cl 0.38 ila 0.85). Bununla birlikte, vajinal progesteron ile plasebo karşılaştırıldığında vajinal progesteronun düşük yapma oranını azaltmada çok az etkisi olduğu veya hiç etkisi olmadığı bulunmuştur (RR $0.75, \% 95 \mathrm{Cl} 0.47$ ila 1.21). Progesteronun oral ve vajinal alt grupları arasındaki uygulama yoluna göre bir fark gösterilmemiştir. Bu çalışma progesteronun DT tedavisinde kullanılabilir olduğuna dair bize yol gösterici olmuştur.

Sadaf ve arkadaşları 2019 yılında oral dihidroprogesteron ve IM progesteronun vajinal kanama üzerine etkisini araştırmışlardır (20). DT olan 552 hasta üzerinde yapılan bu çalışmada Dihidrogesteron (Duphaston $\left.{ }^{\circledR}\right) 10 \mathrm{mg}$ günde 2 oral alan grupta kanama kesilme süresinin haftada $1 \mathrm{kez}$ $250 \mathrm{mg}$ iM progesteron (Proluton depot®) alan gruba göre daha kısa sürdüğü tespit edilmiştir (sırasıyla ortalama 7,0 ve 9,2 gün, $p<0.005$ ).

Yine Beigi A. ve arkadaşlarının 2016 da 109 hasta üzerinde yaptığı çalışmada DT olan hastalarda vajinal progesteron (Cyclogest $₫$ ) ile 17-a -Hidroksi-Progesteron Kaproat (Proluton $囚, I M)$ arasında erken doğum riski karşılaştırılmıştır (21). Gruplar arasında erken doğum eylemi bakımından anlamlı fark saptanmamış.

Serum progesteron seviyesinin düşük olmasının abort riskini artırdığını gösteren çalışmalar bizim çalışmamızın uygulanabilirliğini destekler niteliktedir. 
Chee Wai Ku ve arkadaşlarının 2018 yılında yapmış olduğu tek merkezli, prospektif çalışmasında 5-13 hafta arasındaki normal gebelik serum progesteron sevileri ile aynı hafta içerisindeki düşük riski bulunan ve düşükle sonuçlanan gebelerin serum progesteron seviyelerini karşılaştırımıştır. Çalışmaya 5-13 hafta arası tekil intrauterin gebeliği kesinleşmiş olan 929 gebe dahil edilmiştir. Spontan düşük oranı normal gebe grubunda $\% 5.4$, düşük riski bulunan grupta \%21.5 olarak bulunmuştur $(p<0.0001)$. Düşük riski bulunan grubun ortalama serum progesteronu seviyesi (53.6 $\pm 25.2 \mathrm{nmol} / \mathrm{L})$, normal gebelik grubu (71.8 \pm 27.2 $\mathrm{nmol} / \mathrm{L}$ ) ile karşılaştırıldığında anlamlı olarak daha düşük saptanmıştır ( $p<0.0001)$. Alt grup analizinde, 16 haftalık gebelikte devam eden gebeliği olan kadınlarda ortalama serum progesteron konsantrasyonu, 5 ila 13 haftalık gebelikte lineer olarak artan bir eğilim göstermiştir. Fakat sonunda spontan düşük yapan kadınlarda serum progesteronunda $19.0 \mathrm{nmol} / \mathrm{L}$ den $30.3 \mathrm{nmol} /$ L'ye 5 ila 13 hafta arasında marjinal ve anlamlı olmayan bir artış olduğu saptanmıştır (22). Bu çalışma, düşük serum progesteron seviyesinin düşük riski ve 16. haftadan önce abort ile ilişkili olduğunu ve birinci trimesterda progesteronun önemli rolünü vurgulamaktadır.

Bazı çalışmalarda birbirine üstünlükleri olabileceği belirtilse de genel kanaat vajinal, IM ve oral progesteronun birbirine üstünlüğü olmadığı yönündedir. Ancak son yıllarda kombine kullanımlar artmaktadır. Bizim çalışmamızda da kliniğimizde en çok kullanılan üç progesteron tedavi şekli; vajinal, IM ve vajinal+IM grup olarak değerlendirdi. Bu üç grubun serum progesteron seviyelerini incelediğimiz zaman hem 3. saatteki hem de 7.gündeki serum progesteron artış yüzdeleri vajinal + IM kullanan grupta anlamlı olarak yüksek bulundu. Sadece vajinal ile sadece IM kullanan grup arasında ise anlamlı fark saptanmadı. Çalışmamıza katılan hasta popülasyonunun vajinal kullanım şeklini tam uygulayabilirliği konusu tartışmaya açık olduğundan, IM kullanımın ise erişilebilirlik, abse vb zorluklarından dolayı vajinal+IM kullanımın daha etkili olduğunu söyleyebiliriz.

Bizim bilgilerimize göre birinci trimester DT olan hastaların 3 farklı progesteron tedavi grubu oluşturarak serum progesteron seviyelerini karşılaştıran bir çalışmaya rastlanmamıştır. Ancak çalışmamızın retrospektif olması; hasta sayısının yeterli olmaması, hastaların abortus, preterm doğum ve doğumda gebelik haftalarının gibi obstetrik sonuçlarının araştırmaya katılmaması çalışmanın limitasyonlarıdır.

Sonuç olarak, bu çalışmada vajinal+ IM (kombine) progesteron preparatlarının serum progesteron seviyelerini daha hızlı artıırdığı belirlenmiştir. Bu konuda geniş örneklem büyüklüğü olan ve prospektif çalışmalara ihtiyaç vardır.

Etik onam: Çalışma için Necmettin Erbakan Üniversitesi Meram Tıp Fakültesi Illaç ve Tıbbi cihaz dışı Araştırmalar Etik Kurulundan etik onam alınmıştır (Tarih:10.01.2020; karar no:2020/2269)

\section{Kaynaklar}

1. Siriwachirachai $T$, Jeeraaumponwat T. Effect of Dydrogesterone on Treatment of Threatened Miscarriage: A Systematic Review and MetaAnalyses. Thai J Obstet Gynaecol. 2010;19.

2. Pandian RU. Dydrogesterone in threatened miscarriage: a Malaysian experience. Maturitas. 2009;65 Suppl 1:S47-50.

3. Weiss JL, Malone FD, Vidaver J, Ball RH, Nyberg DA, Comstock CH, et al. Threatened abortion: A risk factor for poor pregnancy outcome, a population-based screening study. Am J Obstet Gynecol. 2004;190(3):745-50.

4. Qureshi NS. Treatment options for threatened miscarriage. Maturitas. 2009;65 Suppl 1:S35-41.

5. Daya S. Luteal support: progestogens for pregnancy protection. Maturitas. 2009;65 Suppl 1:S29-34.

6. Duan L, Yan D, Zeng W, Yang X, Wei Q. Effect of progesterone treatment due to threatened abortion in early pregnancy for obstetric and perinatal outcomes. Early Hum. Dev. 2010;86(1):41-3.

7. Palagiano A, Bulletti C, Pace MC, D DEZ, Cicinelli E, Izzo A. Effects of vaginal progesterone on pain and uterine contractility in patients with threatened abortion before twelve weeks of pregnancy. Ann N Y Acad Sci. 2004;1034:200-10.

8. Sotiriadis A, Papatheodorou S, Makrydimas G. Threatened miscarriage: evaluation and management. BMJ (Clinical research ed). 2004;329(7458):152-5.

9. Tien JC, Tan TY. Non-surgical interventions for threatened and recurrent miscarriages. Singapore Med J. 2007;48(12):1074-90; quiz 90.

10. Miranda S, Litwin S, Barrientos G, Szereday L, Chuluyan E, Bartho JS, et al. Dendritic cells therapy confers a protective microenvironment in murine pregnancy. Scand J Immunol. 2006;64(5):493-9.

11. Yassaee $F$, Mostafaee $L$. The role of cervical cerclage in pregnancy outcome in women with uterine anomaly. J Reprod Infertil. 2011;12(4):277-9.

12. Wahabi HA, Fayed AA, Esmaeil SA, Al Zeidan RA. Progestogen for treating threatened miscarriage. The Cochrane database of systematic reviews. 2011(12):Cd005943.

13. Carp H. A systematic review of dydrogesterone for the treatment of threatened miscarriage. Gynecol. Endocrinol. 2012;28(12):983-90.

14. Kuon RJ, Shi SQ, Maul H, Sohn C, Balducci J, Maner WL, et al. Pharmacologic actions of progestins to inhibit cervical ripening and prevent delivery depend on their properties, the route of administration, and the vehicle. Am J Obstet Gynecol. 2010;202(5):455.e1-9.

15. O'Sullivan MD, Hehir MP, O'Brien YM, Morrison JJ. 17 alpha-hydroxyprogesterone caproate vehicle, castor oil, enhances the contractile effect of oxytocin in human myometrium in pregnancy. Am J Obstet Gynecol. 2010;202(5):453.e1-4.

16. Camuzcuoğlu A , Taner $C$. Erken gebelik kayıplarının değerlendirilmesinde ultrasonografi. Harran Üniversitesi Tıp Fakültesi Dergisi. 2015; 12(1): 103-110.

17. Progesterone supplementation during the luteal phase and in early pregnancy in the treatment of infertility: an educational bulletin. Fertil Steril. 2008;89(4):789-92.

18. Shambhavi S, Bagga R, Bansal P, Kalra J, Kumar P. A randomised trial to compare $200 \mathrm{mg}$ micronised progesterone effervescent vaginal tablet daily with $250 \mathrm{mg}$ intramuscular 17 alpha hydroxy progesterone caproate weekly for prevention of recurrent preterm birth. J Obstet Gynaecol . 2018;38(6):800-6.

19. Wahabi HA, Fayed AA, Esmaeil SA, Bahkali KH. Progestogen for treating threatened miscarriage. Cochrane Database of Systematic Reviews. 2018(8).

20. Maliha Sadaf, Abbasi N. Comparison of Efficacy of Oral Dydrogesterone vsIntramuscular Progesterone in terms of duration of cessation of vaginal bleeding in women with Threatened Abortion. Journal of Rawalpindi Medical College (JRMC. 2019;23(4):194-8.

21. Beigi A, Esmailzadeh A, Pirjani R. Comparison of Risk of Preterm Labor between Vaginal Progesterone and17-Alpha-Hydroxy-Progeste- 
rone Caproate in Women with Threatened Abortion: A Randomized Clinical Trial. Int J Fertil Steril. 2016;10(2):162-8.

22. Ku CW, Allen Jr JC, Lek SM, Chia ML, Tan NS, Tan TC. Serum progesterone distribution in normal pregnancies compared to pregnancies complicated by threatened miscarriage from 5 to 13 weeks gestation: a prospective cohort study. BMC Pregnancy and Childbirth. 2018;18(1):360. 